\title{
Journal of Cellular Plastics
}

http://cel.sagepub.com/

\section{Impact Properties of Natural Fiber-Reinforced Epoxy Foams}

Andrzej K. Bledzki, Jochen Gassan and Wenyang Zhang

Journal of Cellular Plastics 1999 35: 550

DOI: 10.1177/0021955X9903500605

The online version of this article can be found at:

http://cel.sagepub.com/content/35/6/550

\author{
Published by: \\ (9)SAGE \\ http://www.sagepublications.com
}

Additional services and information for Journal of Cellular Plastics can be found at:

Email Alerts: http://cel.sagepub.com/cgi/alerts

Subscriptions: http://cel.sagepub.com/subscriptions

Reprints: http://www.sagepub.com/journalsReprints.nav

Permissions: http://www.sagepub.com/journalsPermissions.nav

Citations: http://cel.sagepub.com/content/35/6/550.refs.html

>> Version of Record - Nov 1, 1999

What is This? 


\title{
Impact Properties of Natural Fiber-Reinforced Epoxy Foams
}

\author{
ANDRZEJ K. BLEDZKI, * JOCHEN GASSAN AND WENYANG ZHANG \\ Universität (Gh) Kassel \\ Institut für Werkstofftechnik-Kunststoff-und Recyclingtechnik \\ Mönchebergstraße 3 \\ 34109 Kassel, Germany
}

\section{INTRODUCTION}

\begin{abstract}
Tatural fiber is a renewable and low priced natural resource. 1 Polymers reinforced with these fibers are a relatively new class of material with good economical and ecological outlooks. Due to the chemical composition and physical structure of the fibers, their composites have a relatively good overall mechanical behavior with a low specific mass (high stiffness and high tensile strength per unit weight). Moreover, the possibility to "recycle" natural fiber composites by combustion, as well as the fact that the fibers are a re-growing resource, is a contribution to the environmental compatibility of these materials. Therefore natural fibers as reinforcements for plastics are widely and increasingly used in technical applications, e.g., in interior components of cars and trucks, such as door linings, parcel rack and column trim [1,2]. Natural fiber (e.g., flax or sisal) reinforced-foamed materials seem to be new and interesting materials which are still poorly characterized [31,32].

In general, the impact behavior of composite laminates in engineering applications is of main importance. Structure of the textiles, fiber type and content, matrix ductility and void content of the composite are the main structural parameters which affect the impact behavior. The im-
\end{abstract}

*Author to whom correspondence should be addressed. 
pact resistance is the ability of a material and its structure to survive impact induced damages during an impact event. This behavior can be described by two separate issues:

1. Force-deflection (or time) curve: The force-deflection (or time) curve refers to associate damage initiation by the first significant change in the slope of the curve (see Figure 1) [6,22-24], which is especially attributed to matrix cracking for brittle thermosets during the impact event [9-11].

2. Characteristic values: Loss energy (Wv) as a measure of energy dissipation, strain energy (Ws) as a measure of the energy stored and the damping index $\left(\Lambda^{*}\right)$ as a ratio of loss-energy to strain energy $[6,7]$.

As mentioned before, impact resistance can be affected by a number of factors. For instance, polyethylene fiber-reinforced epoxy has a higher impact strength and higher ductility due to the high strength and strain of the polyethylene fibers than the composites containing polyester and polyamide (nylon) fibers. Furthermore, increasing the fiber content can significantly enhance in some cases the total energy absorbed by the composite materials in complete penetration [25]. Carbon fiber based composites with different polymer matrix systems (such as epoxies, impact-modified epoxies, and amorphous and semicrystalline thermoplastics) behave in a different way to impact induced damages. By using the same energies of impact, the highly crosslinked brittle epoxy material showed the greatest damage, while

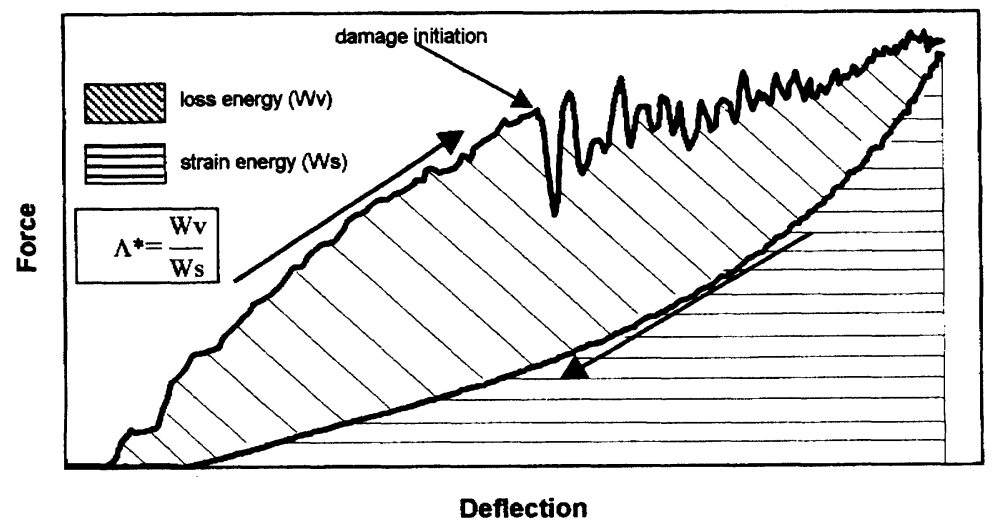

Figure 1. Typical impact force-deflection curve with characteristic values for natural fiber-reinforced epoxy-foams (30 vol.-\% flax fiber, non-foamed). 
the impact-modified epoxy based composites and the amorphous polyimide material showed the lowest [16].

The impact resistance is further affected by the structure of the reinforcement. For woven fabric based composites, the impact strength and the ductility index of 3-D woven epoxy resin composite was higher than that of 2-D woven composite [11]. Quasi-isotropic laminates require more energy than unidirectional prepreg tape composites with the same type of resin [30].

Enhancing applied impact energies, an almost linear increase of the maximum force and damaged areas (measured by $\mathrm{C}$-scan technique) were detected $[16,29]$. In general, void-free composites show a better impact resistance than foamed ones [7,14,20,27,28]. However, the highest impact strength was observed for glass fiber-reinforced polyurethane foams with a void content of $2.1 \%$, while the specimens with the highest void content (approximate 9\%) led to a maximum load, which was $13 \%$ lower than for that with 2.1 vol.-\% [29]. For glass reinforced epoxy foams, the impact properties exhibited more or less a linear relationship to the void content $[7,20]$.

Plenty of references $[10,16-20,24-26]$ deal with the investigations on the impact response, damage configuration, the damage initiation and propagation during the impact. Laminated composites under impact loads exhibit a compressive indentation at the impact side; this indentation is a response to the elastic stiffness and deformation capacity referred to as the composite strength and toughness [25,26]. In general, impact damage causes a complicated pattern of matrix cracks. This pattern at a transverse section through the impact center was depicted by a cone with the complexity of the delamination and cracking network $[10,16-19,24]$. The crack run at this conical pattern for thermoplastic high-density foam (PPO and PC foam) [5] and woven glass fiber-reinforced epoxy resin foam [20] was observed with a fracture angle of nearly $45^{\circ}$.

The impact on the specimen causes crushing by the high concentration of the impact energy absorbed. Meanwhile, deflection is induced due to a rapid diffusion and decay process of the energy absorbed from the impact surface to the back surface. This process accompanies the emerging of matrix cracks and delaminations by flexural tensile stress and interlaminar shear stress [6,9-11,26]. Especially for fiber-reinforced foams, cracks can easily propagate through the void regions, which leads to lower impact resistance $[5,20]$.

In the present study, impact tests were carried out on laminated epoxy-based composites with jute and flax fiber based wovens as reinforcement by using different impact energies. 


\section{EXPERIMENTAL}

The materials used and their suppliers are given in Table 1. An epoxy resin based foam was used as a polymer matrix. As reinforcement, woven jute and flax yarn were used with a length of 20 to $40 \mathrm{~mm}$ and a diameter of $37 \mu \mathrm{m}$ and $20 \mu \mathrm{m}$ for the jute and flax elementary fibers, respectively. Before composite processing, the woven fabrics were pretreated with benzene/methanol-solution to dewax the textiles. The composites were processed by using GLS-technique (Europ. Patent No. 69076) on a laboratory press at a temperature of about $80^{\circ} \mathrm{C}$ for $15 \mathrm{~min}$. Impact specimens of dimensions $50 \times 50 \times 2 \mathrm{~mm}^{3}$ were cut from these laminates plates.

Specimens with different fiber contents ( $0-40$ vol.- $\%$ in five steps) and void contents $(0-40$ vol. $-\%$ in five steps $)$ were investigated throughout this study. The optical microscope investigations indicate that the voids of the foamed composites are distributed evenly in the interphase and resin-rich zones between the fiber yarn. The cellular structure of the non-reinforced and reinforced foams is the same.

The specimens were tested, using a "low-velocity falling weight impact" tester at room temperature in non-penetration-mode. The impactor had a mass of $0.75 \mathrm{~kg}$. Three impact energies, $0.96,1.47$, and 1.85 Joules, were chosen for each type of composite by varying the falling height. The impact induced force was determined by a load transducer with a piezoelectric quartz on the impactor tup; the deflection was determined by using a position sensitive detector. The raw data were stored digitally and were illustrated in a force-deflection curve (hysteresis loop). As shown in Figure 1, damage initiation is defined by the first significant drop of the force. Additionally, loss energy and damping index were calculated and used throughout this study. Here, the loss energy involves vi-

Table 1. Materials used.

\begin{tabular}{lcccccc}
\hline & $\begin{array}{c}\text { Density } \\
\left(\mathrm{g} / \mathrm{cm}^{3}\right)\end{array}$ & $\begin{array}{c}\text { Aerial } \\
\text { Weight } \\
\left(\mathrm{g} / \mathrm{m}^{2}\right)\end{array}$ & $\begin{array}{c}\text { Weave Set } \\
\text { Warp/Weft } \\
(10 \mathrm{~cm})\end{array}$ & $\begin{array}{c}\text { Fineness } \\
(\text { Yarn }) \text { Tex }\end{array}$ & $\begin{array}{c}\text { Twisted Angle } \\
(\text { Yarn }) \\
(\mathrm{t} / \mathrm{m})\end{array}$ & Supplier \\
\hline $\begin{array}{l}\text { Natural Fiber, woven } \\
\text { fabric }\end{array}$ & 1.31 & 262 & $51 / 51$ & 280 & 277 & $\begin{array}{c}\text { J. Schilgen } \mathrm{GmbH} \\
\text { \& Co Germany }\end{array}$ \\
$\begin{array}{l}\text { Flax, woven } \\
\text { fabric }\end{array}$ & 1.50 & 277 & $51 / 50$ & 277 & 277 & $\begin{array}{c}\text { J. Schilgen GmbH } \\
\text { \& Co Germany }\end{array}$ \\
\hline $\begin{array}{l}\text { Resin System } \\
\text { Resin: Araldit LY 5054 }\end{array}$ & Mixing Proportion & Hardening Condition & Supplier \\
$\begin{array}{l}\text { Hardener: XB5003-1 } \\
\text { Foaming agent: DY5054 }\end{array}$ & $100: 20: 0-2$ & $80^{\circ} \mathrm{C}$ for 15 min & Ciba Geigy, \\
Germany
\end{tabular}


brational energy, plastic energies based on irreversible deformations, energy dissipation due to creation of matrix cracks and their propagation, delaminations and finally fiber fracture.

\section{RESULTS AND DISCUSSION}

The general effect of fiber content on the impact behavior of the composites were similar for both types of fiber based composites used. Because of this, the general effects are discussed best on the results of the woven flax fiber, non-foamed composites (Figure 2). The given force-deflection curves were measured by an impact energy of 0.96 Joule. Here 12 vol.-\% fiber content of non-foamed composite showed inferior impact resistance. With increasing fiber content, the impact strength (maximum force) and impact stiffness increases significantly. For instance, between the two limits of fiber content investigated, the force and deflection for damage initiations were increased by about $79 \%$ and decreased by about $40 \%$, respectively. In the same way, the impact maximal force and maximal deflection for composites with a fiber content of 40 vol.-\% were about $104 \%$ higher and $50 \%$ lower, respectively, than that with a fiber content of 10 vol.- $\%$.

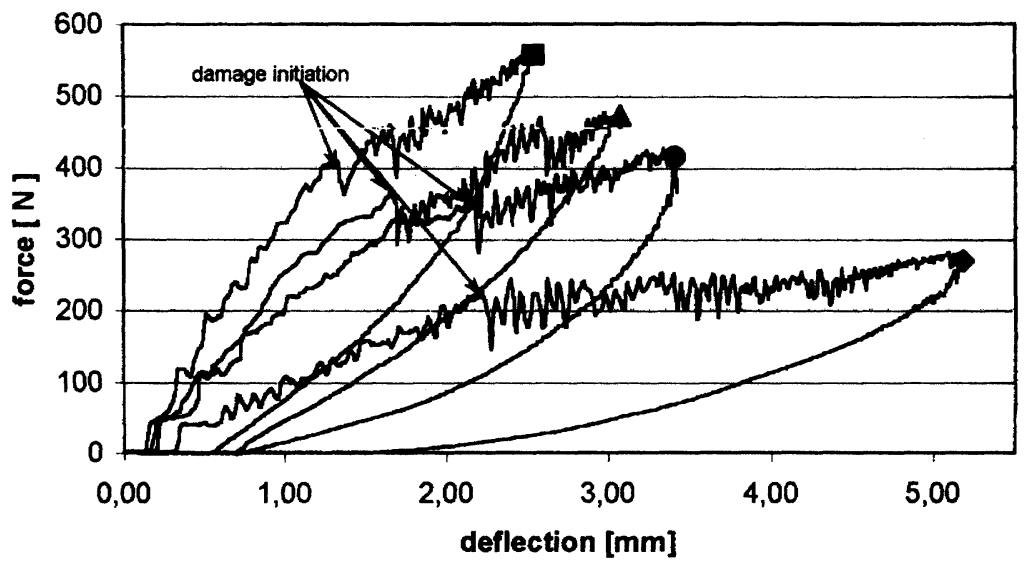

12 vol.-\% fiber content 30 vol.-\% fiber content

21 vol.-\% fiber content 40 vol.-\% fiber content

Figure 2. Effect of fiber content on "force-deflection"; woven flax fiber reinforced laminates (non-foamed); impact energy of 0.96 Joules. 
It is noted that all composites investigated exhibited a very similar general trend for the loss energy and the damping index versus fiber content with a constant void content and impact energy. Figure 3 illustrates the relationship between the characteristic values and fiber content of the non-foamed and foamed composites for an impact energy of 0.96 Joule. For about 10 vol.- $\%$ fiber content for the woven jute, the loss energy was not measurable because the specimens were penetrated at the impact energy of 0.96 Joules. A more significant decrease was observed for both loss energy and damping index of the woven flax non-foamed composites between a fiber content of 12 to 22 vol.- $\%$, while the decrease above 22 vol. $-\%$ was less significant [Figure 3(a)]. A comparison of the loss energy and damping index between the non-foamed and foamed composites (flax woven) is given in Figure 3 (b). It becomes clear that the void content greatly influenced the loss energy and damping index, especially for lower fiber contents at the same impact energy. As the fiber content increases from approximately 20 to $40 \mathrm{vol} .-\%$, the differences between both types of the composite were gradually reduced.

Furthermore, it was found that the flax fiber based composites generally exhibit a better impact resistance under comparable test conditions. These results can be attributed to the fact that flax fibers have a higher strength than jute fiber $[3,4,12,13]$. This fact can also be ob-

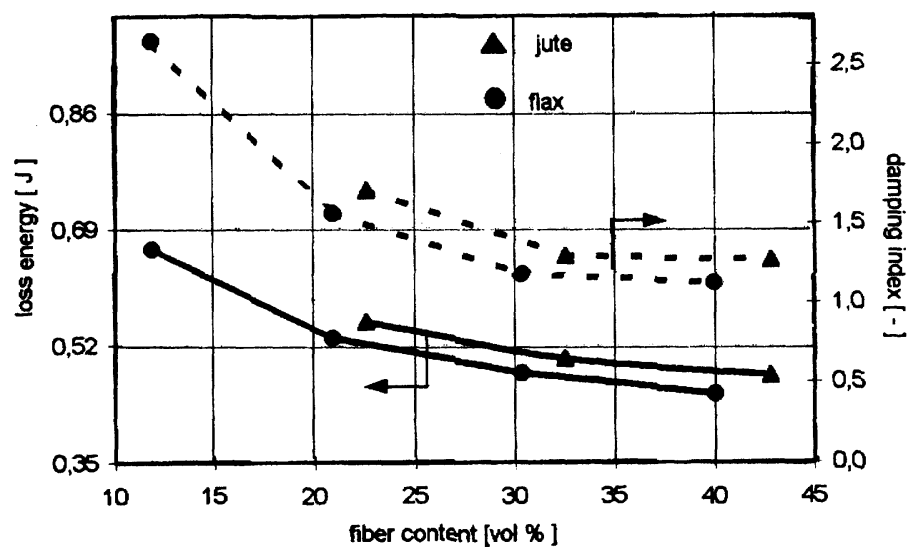

(a)

Figure 3. Fiber content as function on loss energy; falling energy of 0.96 Joules: (a) woven jute and flax non-foamed composites; (b) woven flax composites. 


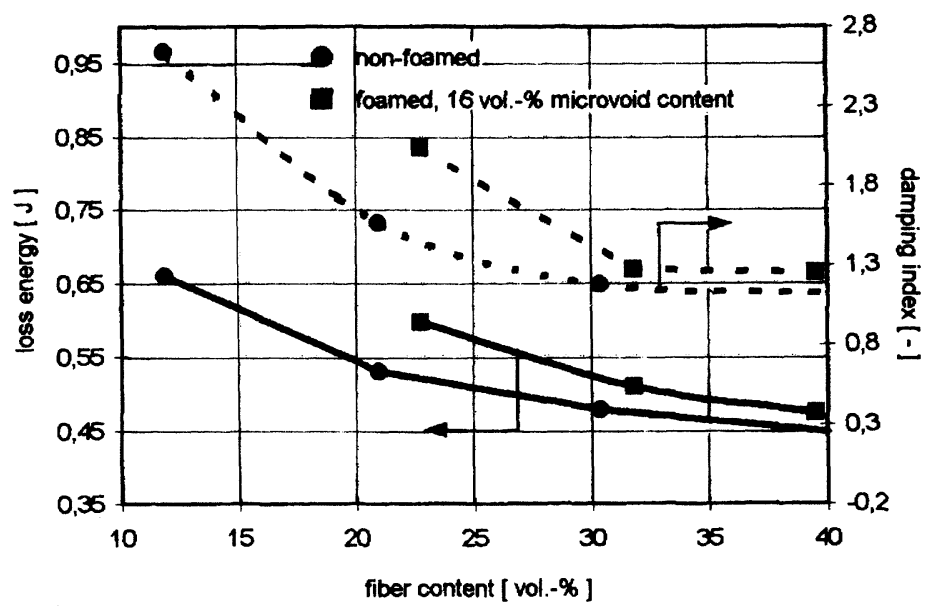

(b)

Figure 3 (continued). Fiber content as function on loss energy; falling energy of 0.96 Joules: (a) woven jute and flax non-foamed composites; (b) woven flax composites.

tained by comparing the force-deflection-curve of woven jute and flax for the foamed composites under 1.5 Joule impact energy, as done in Figure 4. The results indicate that the impact resistance for the woven jute fabric was significantly lower than that for flax; its damage initiation force and maximal force were $37 \%$ and $29 \%$, respectively, lower, and the maximum deflection $51 \%$ higher than the woven flax fabric, but the deflections for damage initiation of both composites were very close.

It can be verified that the damage is built by matrix cracks and isolated fiber fractures as shown in the results of the optical microscope investigations at low magnifications. A crack runs through the thickness of the laminate towards the back surfaces with an angle close to $45^{\circ}$ with respect to the vertical. This typical failure is shown in Figures $5(a, b)$ for the woven flax fiber reinforced foamed-laminates. Similar failures were also observed for jute woven composites. For the foamed composites, it is visible that the cracks were built or propagated through voids resin-rich zones between the woven fiber yarn. The mechanism, if the crack is formed by a void and stopped by it, is still unknown; both can be possible.

As mentioned before, the impact behavior is significantly affected by the void content of the composites. In general, an increase of void content 


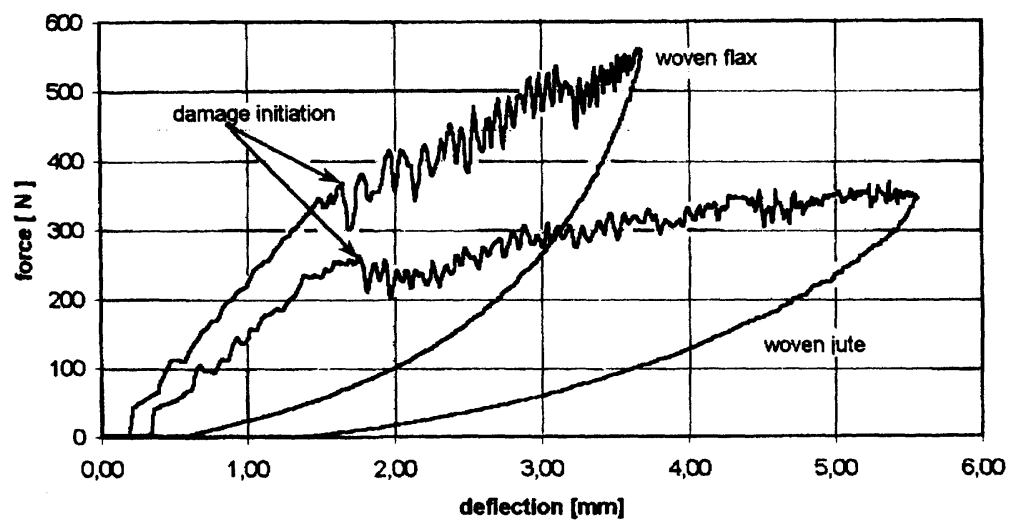

Figure 4. "Force-deflection-curve" of impact tests of different jute and flax epoxy-foams; (16 vol.-\% void content; 30 vol.-\% fiber content; impact energy of 1.5 Joules).

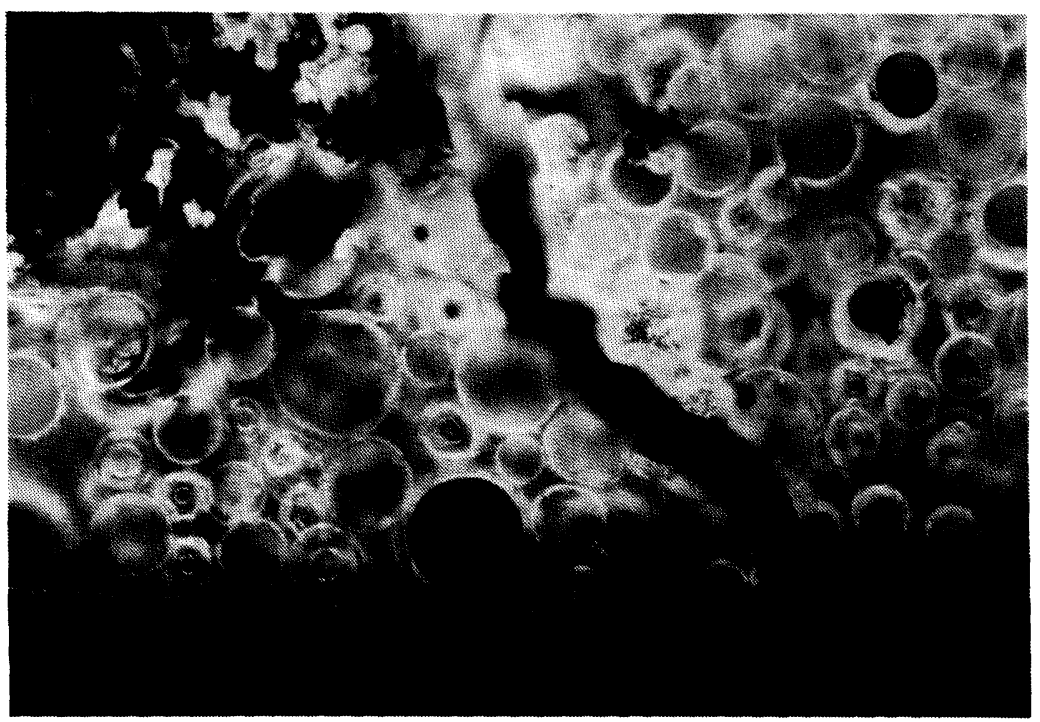

(a)

Figure 5. Optical micrograph of a transverse crack in woven flax fiber reinforced epoxy-foams; magnification of 1:100; impact energy of 1.5 Joules, 35 vol.-\% void content; 30 vol.-\% fiber content. 


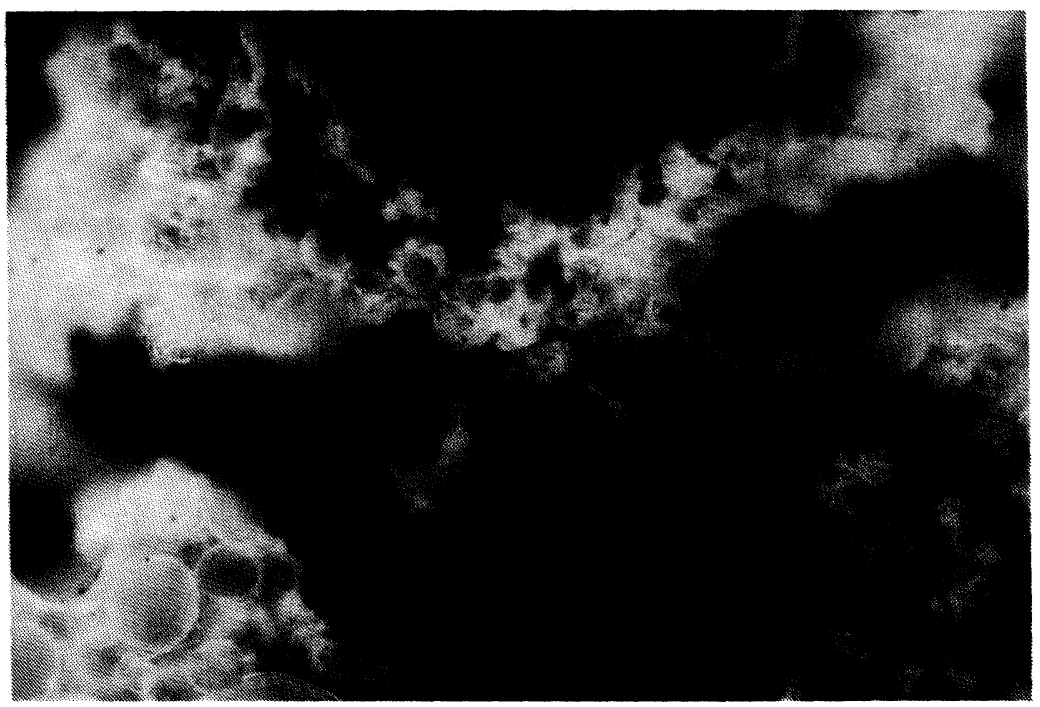

(b)

Figure 5 (continued). Optical micrograph of a transverse crack in woven flax fiber reinforced epoxy-foams; magnification of 1:100; impact energy of 1.5 Joules, 35 vol.- $\%$ void content; 30 vol.-\% fiber content.

tends to reduce maximal force, but the composite deflection was enhanced, as shown in Figure 6, for the woven flax fiber based composites. The non-foamed composites with a void content of 0.5 vol.-\% reached the highest impact force. By increasing the void content from 0.5 to 35 vol.- $\%$, the initial damage and maximal force were reduced by about $28 \%$ and $20 \%$; similarly, the deflection of the damage initiation and maximal deflection were increased by $38 \%$ and $52 \%$, respectively.

Furthermore, an almost linear relationship between the characteristic values (loss energy and damping index) and void content was observed for all composites by using comparable fiber contents. A higher void content generally leads to a greater loss energy and damping index. Figure 7 shows that the effect of void content on the loss energy and damping index is very similar for woven flax and jute reinforced epoxy-foams. For the woven flax, an increase of void content from 0.5 to 30 vol.- $\%$ tends to increase the loss energy by about 14\%; the damping index increases by about 53\% for a fiber content of 30 vol.- $\%$ and an impact energy of 1.5 Joule.

For all tests, increasing the falling energy also induces an almost linear increase for the loss energy and the damping index under comparable void and fiber content. The relation between the change of falling energy 


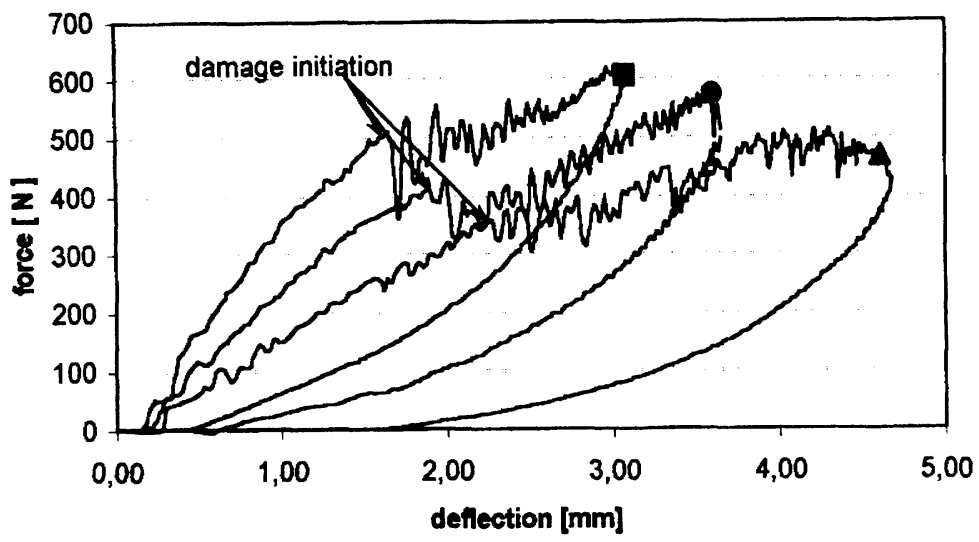

- 0,5 vol. $-\%$ void content

16 vol. $-\%$ void content

A 35 vol. $-\%$ void content

Figure 6. Effects of void content on "force-deflection"; $30 \%$ flax fiber content; falling energy of 1.5 Joules.

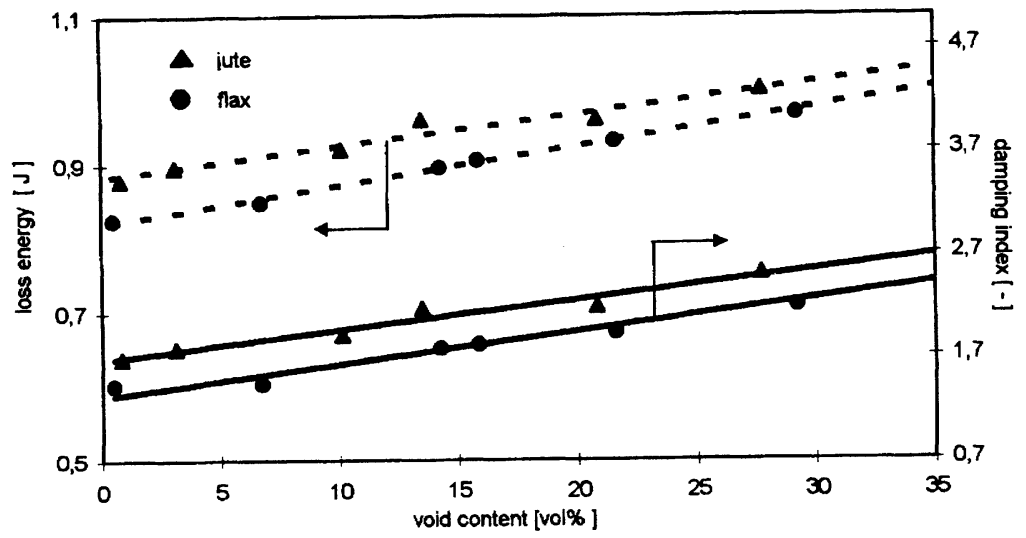

Figure 7. Influences of void content on the loss energy and damping index of woven and jute flax reinforced epoxy foams ( 30 vol.. $\%$ fiber content, falling energy 1.5 Joules). 


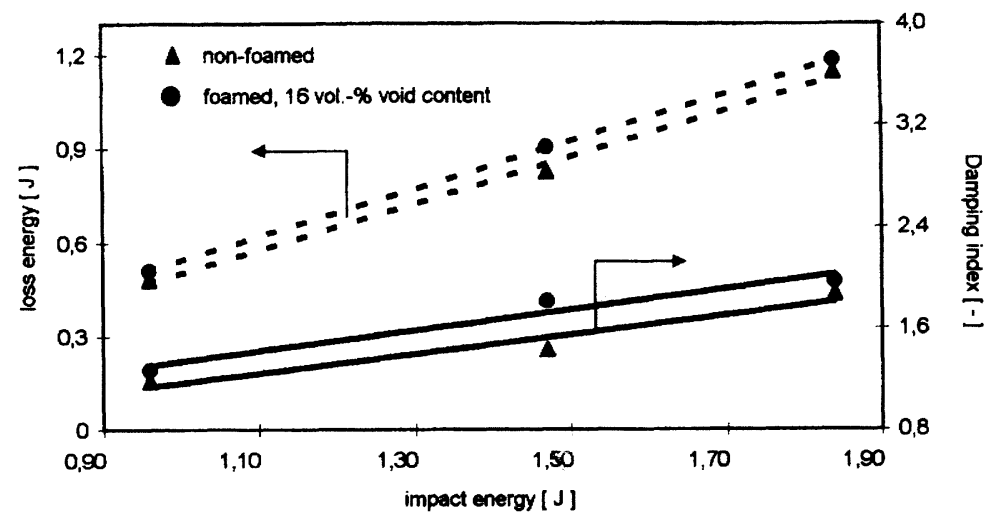

Figure 8. Variety of impact energy as a function on loss energy and damping index; $30 \%$ flax fiber content.

and the impact properties is represented in Figure 8 for the flax fiber reinforced non-foamed and foamed composites of 30 vol.-\% fiber content. The loss energy and damping index was higher when the falling energy became larger.

\section{CONCLUSIONS}

The influence of various fibers, fiber contents and void content on the impact behavior of the natural fiber-reinforced epoxy-foams was investigated in this study.

Increasing the fiber content enhances the impact strength and decreases the loss energy and the damping index of the composites. It was observed that the effect of the voids on the impact behavior at a higher fiber content is less. The flax fiber based composites exhibit a better impact resistance than the jute fiber based ones, due to a higher strength and stiffness of the flax fiber.

It was significant that the void content in the composites affects the impact resistance. The results showed that increasing void content decreases the impact strength and increases maximum deflection of the composite. With increasing void content and impact energy, the loss energy and the damping index exhibited an approximate linear increase under comparable test conditions.

Optical microscope investigations showed that the cracks were easily formed and propagated through the void-rich zones. 


\section{REFERENCES}

1. Schuh, Th. 1997. "Naturfasern in Automobilanwendungen," Verbundwerkstoffee und Werkstoffuerbunde, Tagung in Kaiserslautern, Germany, pp. 67-84.

2. Schlößer, Th. and Th. Fölster. 1996. Kunststoffe, 85:319-321.

3. Fölser, Th. and W. Michaeli. 1993. Kunststoffe, 83:687-691.

4. Sridhar, M. K. 1982. "Evaluation of Jute as a Reinforcement in Composites," Indian Journal of Textile Research, 7:87-92.

5. Throne, J. L. 1985. Journal of Cellular Plastics, 21:123-140.

6. Gassan, J. and A. K. Bledzki. 1997. Gummi Fasern Kunststoffe, 50:360-364.

7. Bledzki, A. K., K. Kurek, G. Wacker and J. Gassan. 1995. Materialprüfung, 37:360-364.

8. Nagy, A. 1974. Journal of Cellular Plastics, 10:127-133.

9. Bibo, G. A. and P. J. Hogg. 1996. Journal of Materials Science, 31:1115-1137.

10. Lammerant, L. 1994. Composites Science and Technology, 51:505-517.

11. Chou, S., H.-C. Chen and H.-E. Chen. 1994. Composites Science and Technology, 51:23-35.

12. Höck, P. 1994. "Verstärken von Polypropylen mit Flachsfasern-Einsatz von Haftvermittlern," 17.IKV-Kolloquium, Aachen, pp. 230-235.

13. Gassan, J. and A. K. Bledzki. 1998. "Zum Ermüdungsverhalten naturfaserverstäkter Kunststoffe," 5. Internationale Tagung Stoffliche Nutzung nachwachsender Rohstoffe, Chemnitz, pp. 119-123.

14. Kishore, S. V. 1998. Journal of Applied Polymer Science, 67:1565-1571.

15. Bibo, G. A., P. J. Hogg and M. Kemp. 1995. 3rd International Conference on Deformation and Fracture of Composites, University of Surrey, Guildford, UK, pp. 374-383.

16. Srinivasan, K., W. C. Jackson, B. T. Smith and J. A. Hinkley. 1992. Journal of Reinforced Plastics and Composites, 11:1111-1126.

17. Joshi, S. P. and C. T. Sun. 1985. Journal of Composite Materials, 19:51-66.

18. Clark, G. 1989. Composites, 20:209-214.

19. Preuss, T. E. and G. Clark. 1988. Composites, 19:145-148.

20. Kurek, K. 1993. "Einfluß von Mikroporen auf das Mechanische Verhalten von Faserverbundwerkstoffen," PhD doctoral dissertation of the University of Kassel, Kassel, Germany.

21. Briscoe, B. J., R. S. Court and D. R. Williams. 1993. Composites Science and Technology, 47:261-270.

22. Kessler, A., A.K. Bledzki and G. Wacker. 1997. "Einfluß der Grenzschlicht auf die Dämpfungseigenschaften von unidirektional verstärkten Glas/Epoxidharz-Verbunden unter Impactbelastung," Verbundwerkstoffe und Werkstofferbunde-Tagung, Kaiserslautern, Germany, pp. 395-401.

23. Rice, D. M. and R. J. G. Dominguez. 1983. Journal of Cellular Plastics, 19:114-120.

24. Davies, P., D. Choqueuse and A. Pichon. 1994. ECCM-CTS2, Hamburg, Germany, pp. 513-523.

25. Jang, B. Z., L. C. Chen, C. Z. Wang, H. T. Lin and R. H. Zee. 1989. Composites 
Science and Technology, 34:305-335.

26. Wu, E. and K. Shyu. 1993. Journal of Composite Materials, 27:1443-1463.

27. Bledzki, A. K., K. Kurek and J. Gassan. 1998. Journal of Materials Science, 33:3207-3211.

28. Patterson, J. 1998. Journal of Vinyl \& Additive Technology, 4:26-29.

29. McGeehan, J. A., J. Gillespie and J. Hulway. 1993. Polymer Engineering and Science, 33:1627-1633.

30. Bibo, G. A., P. J. Hogg and M. Kemp. 1995. Deformation and Fracture of Composites, 3rd International Conference, University of Surrey, Guildford, pp. 374-38.

31. N. N. 1998. Kunststoffe, 88:1252-1253.

32. Stokke, D. D., S. M. Shaler and R. N. Hawke. 1992. SAMPE Quarterly, 23:58-64. 